\title{
The Hospitalist Huddle: a I-year experience of teaching Hospital Medicine utilizing the concept of peer teaching in medical education
}

This article was published in the following Dove Press journal: Advances in Medical Education and Practice

\section{Mohammed Elhassan}

Department of Internal Medicine, Division of Hospital Medicine, UCSF/ Fresno Center for Medical Education and Research, Fresno, CA, USA

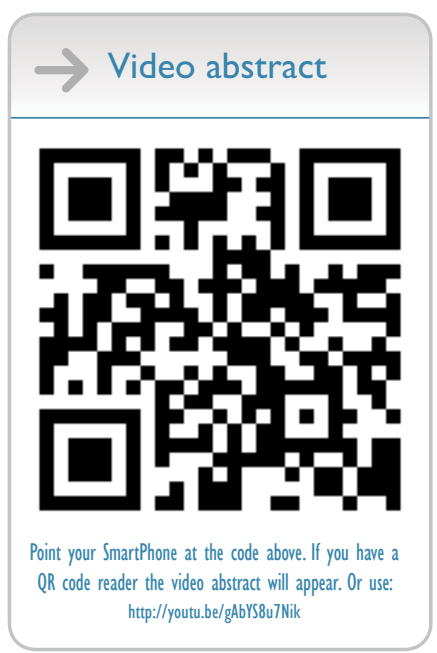

Correspondence: Mohammed Elhassan Department of Internal Medicine, Division of Hospital Medicine, UCSF/ Fresno Center for Medical Education and Research, I $55 \mathrm{~N}$ Fresno St, Fresno, CA 9370I, USA

Tel + I 5594996500

Fax + I 559499650 I

Email melhassan@fresno.ucsf.edu
Background: The relatively new specialty of Hospital Medicine in the USA is one of the fastest growing fields in internal medicine. Academic hospitalists are largely involved in the medical education of postgraduate residents and medical students. Little is known about the effectiveness of peer-to-peer teaching in internal medicine residency training programs and how the medical residents perceive its educational value in learning Hospital Medicine.

Materials and methods: The Hospitalist Huddle is a weekly educational activity newly established by our Hospitalist Division to facilitate the concept of peer-to-peer teaching. It requires medical residents to teach and educate their peers about the clinical topics related to Hospital Medicine. Faculty hospitalists serve as facilitators during the teaching sessions. A survey disseminated at the end of the first year of its implementation examined the residents' perception of the educational value of this new teaching activity.

Results: Most residents reported that they see the Huddle as a useful educational forum which may improve their skills in teaching, create a better educational and learning environment during their inpatient rotation, and improve their understanding of Hospital Medicine. Most residents also prefer that their peers, rather than faculty hospitalists, run the activity and do the teaching.

Conclusion: The survey results support the notion that teaching and learning with flat hierarchies can be an appealing educational method to medical residents to help them understand Hospital Medicine during their medical wards rotation. Some areas need to be improved and others need to be continued and emphasized in order to make this novel educational activity grow and flourish in terms of its educational value and residents' satisfaction.

Keywords: graduate medical education, peer-to-peer teaching, teaching Hospital Medicine, medical residents' education

\section{Introduction}

The term "hospitalist" was first coined by Drs Wachter and Goldman in their paper which discussed the evolving role of general internal medicine physicians who specialized in caring for patients admitted to hospitals and other health care facilities. ${ }^{1}$ Since then, Hospital Medicine in the USA has been one of the fastest growing fields in internal medicine. ${ }^{2}$ It is now a career choice for a substantial proportion of graduating internal medicine residents. ${ }^{3}$ A subset of hospitalists, known as academic hospitalists, are largely involved in medical education. They supervise internal medicine residents and medical students during their rotations in general medical wards, high dependency units, and, sometimes, intensive care units. In fact, teaching and research are important aspects of the Hospital Medicine movement, and the Society 
of Hospital Medicine emphasized this notion in its definition of a hospitalist. ${ }^{4}$ Therefore, academic hospitalists should make all efforts to create ideas that enhance their learners' educational experience during this important rotation of their residency training.

Peer-to-peer teaching is one promising approach that has been shown to enhance learning and foster leadership skills in medical education. ${ }^{5}$ However, little is known about its effectiveness in internal medicine residency training programs and how the medical residents perceive its educational value in learning Hospital Medicine. This article describes the implementation of a novel hospitalist-supervised peer-topeer teaching intervention in an internal medicine residency program and examines the learning outcomes reported by participating residents. This new teaching activity was named the Hospitalist Huddle.

\section{Materials and methods}

The Division of Hospital Medicine inaugurated the Hospitalist Huddle at the beginning of 2016-2017 academic year in a large academic safety-net community hospital in Central California, USA. It is a 30-minute, weekly activity at which time the second- or third-year postgraduate medical resident (the PGY-2 or PGY-3, respectively) who leads one of the three teaching services rotating in general medical wards in our facility is assigned to teach and discuss a topic related to Hospital Medicine with the rest of the residents, interns, and medical students. Each team, supervised by one academic hospitalist, has one PGY-2 or PGY-3 resident, at least two interns and, on many occasions, one or two medical students. The presenting PGY-2 or PGY-3 has the freedom to choose any topic as long as it is related to Hospital Medicine, has educational value as per their judgment, and is related to their daily practice in medical wards. All team members who are available during the meeting time are required to attend. The presenting resident leads the discussion, asks and answers questions as required, with at least one faculty hospitalist present to serve as a facilitator. At the end of the 2016-2017 academic year (after 1 year of implementation), an anonymous electronic survey was sent to all residents to obtain feedback about their perception of the educational value of this novel educational practice.

\section{Results}

Twenty-two residents $(\mathrm{N}=22)$ responded to the survey (eleven were interns, seven were PGY-2s, and four were PGY-3s) with a response fraction of $35 \%$. Most residents (56\%) attended three or four sessions throughout the academic year, eight residents $(36 \%)$ attended one or two, and two residents were able to attend five or more sessions. Examples of the topics that were discussed include: inpatient management of seizures, a diagnostic challenge of a case with jaundice, causes and management of acute upper gastrointestinal bleeding, radiation oncology for internists, and others. Of all the residents who responded to the survey, $87 \%$ mentioned that they were either "satisfied" (64\%) or "very satisfied" (23\%) with the Huddle overall as an "educational experience" and that it was either "very useful" or "probably useful" (Figure 1).

The Huddle was created to take place every Thursday afternoon (between 1:15 and 1:45 PM) as there is no other teaching activity for residents on that day, and the afternoon gives residents enough time to finish their post-rounding orders and to make sure they have already had their lunch. The team assigned to present the Huddle is the team in which

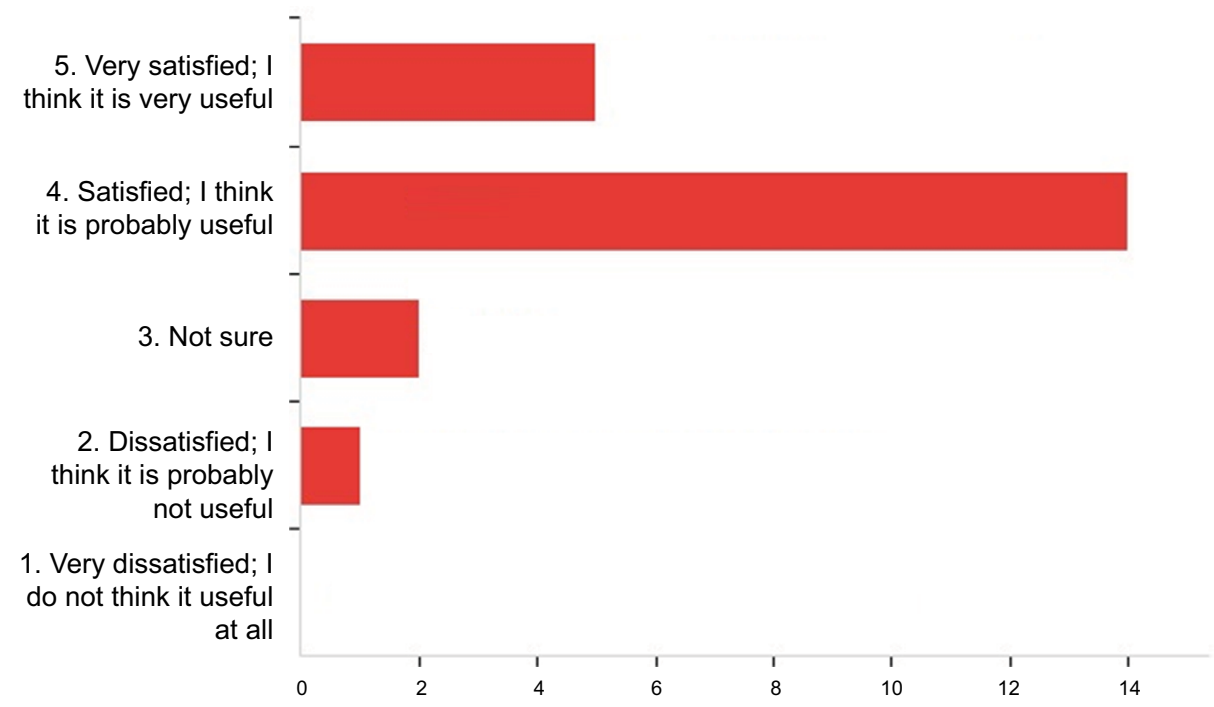

Figure I The number of residents who responded to the question: "Overall, how would you rate your educational experience in the Huddle?" 
the leading resident has that Thursday as a pre-call day (usually this is the least busy day). Nineteen residents (86\%) mentioned that this timing schedule is either "extremely reasonable" or "somewhat reasonable". No resident thought that the timing is "unreasonable" or suggested an alternative schedule. As far as the duration of the Huddle is concerned, which is about 30 minutes, 19 residents $(86 \%)$ agreed this duration of time is "reasonable".

The presenting resident was given the freedom to decide on their Hospital Medicine topic that they would like to teach and also on the delivery method. All of the assigned residents picked a topic relevant to Hospital Medicine. Some of them based their discussion on a real case and others on a theoretical case and some without discussing a case at all. Most of the residents decided to present using Microsoft PowerPoint ${ }^{\mathbb{B}}$ and a few used "hand-outs". On the survey, the formats that were most favored by the residents were those which were based on clinical cases (Table 1).

When asked about whether they agreed that the Huddle "helps second and third year residents develop their teaching skills more", most residents (68\%) selected "probably yes" and three residents (14\%) selected "definitely yes". They were also asked whether they agreed that the Huddle "helps interns learn and understand acute and Hospital Medicine better", and 13 residents (59\%) said "probably yes" and five residents (23\%) said "definitely yes". They were also asked whether they agreed that the Huddle "gives residents useful clinical pearls about how to manage patients in the general medical wards rotation", and similar results were obtained with most residents (64\%) picking "probably yes" and five residents (23\%) choosing "definitely yes". The most positive response obtained was the question that asked whether the Huddle "creates a better environment for medical education and learning during general medical wards rotation", with most residents (41\%) responding "definitely yes" and eight residents (36\%) saying "probably yes" (Figure 2).

Another question of interest was whether the residents (given their usually busy ward work) would like to have faculty hospitalists prepare and present the topic rather than the current format in which PGY-2s and PGY-3s do the

Table I The number of residents who ranked each field that represents a Huddle structure

\begin{tabular}{|c|c|c|c|c|c|c|}
\hline & & $\begin{array}{l}\text { Rank I, } \\
\text { n (\%) }\end{array}$ & $\begin{array}{l}\text { Rank 2, } \\
\text { n (\%) }\end{array}$ & $\begin{array}{l}\text { Rank 3, } \\
\text { n (\%) }\end{array}$ & $\begin{array}{l}\text { Rank 4, } \\
\text { n (\%) }\end{array}$ & $\begin{array}{l}\text { Rank 5, } \\
\text { n (\%) }\end{array}$ \\
\hline I. & $\begin{array}{l}\text { Case presentation by the resident with questions from history to diagnosis } \\
\text { (similar to the classic morning report) }\end{array}$ & $7(35)$ & $5(25)$ & $2(10)$ & $4(20)$ & $2(10)$ \\
\hline 2. & The resident presents a brief case and then talks about the topic related to the case & $4(20)$ & $10(50)$ & $2(10)$ & $4(20)$ & 0 \\
\hline 3. & The resident directly presents a topic and talks about it & $4(20)$ & $3(15)$ & 9 & $4(20)$ & 0 \\
\hline 4. & $\begin{array}{l}\text { Questions and answers only: the resident discusses MKSAP or similar fashioned } \\
\text { questions related to the topic throughout the session }\end{array}$ & $4(20)$ & $2(10)$ & $7(35)$ & $7(35)$ & 0 \\
\hline 5. & Other; please specify & I (5) & 0 & 0 & I (5) & $18(90)$ \\
\hline
\end{tabular}

Note: Residents ranked each field from I to 5 in response to the question: "Please rank the following Huddle structures that you would like to see more during the Huddle, with I being the one you like the most and 5 the least".

Abbreviation: MKSAP, Medical Knowledge Self Assessment Program.

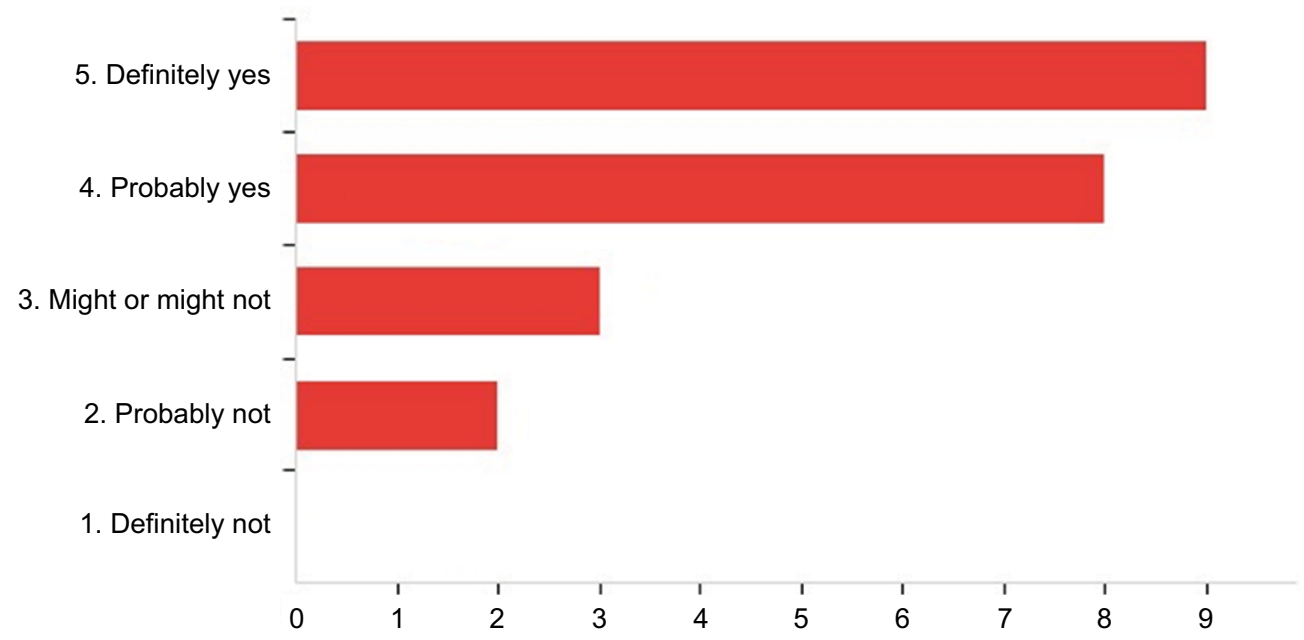

Figure 2 The number of residents who answered the question: "What's your degree of agreement: The Huddle creates a better environment for medical education and learning during general medical wards rotation?" 
teaching. Thirteen residents wanted to keep it "the way it is now" and one actually preferred interns to "prepare the topic and present during the Huddle". There were seven residents who preferred the attendings to run the Huddle. In all, a total of 14 residents $(62 \%)$ preferred their peers to be the ones responsible for preparing and teaching during the Huddle.

\section{Discussion}

Most of the residents appeared to appraise the Huddle as a valuable educational experience. They were also satisfied with its scheduling format. Choosing a suitable day, time, and duration is important. The Division of Hospital Medicine wanted to make sure that residents were satisfied with the Huddle schedule to avoid the possibility that this new activity would interfere with their clinical responsibilities. The resident is excused if they have an outpatient clinic schedule on that afternoon or have an acutely sick patient to evaluate.

As expected, linking theory to practice was shown to be the most preferred method chosen by our learners when it comes to understanding a topic in Hospital Medicine. This is referred to as case-based learning (CBL) and can be defined as: "The goal of CBL is to prepare students for clinical practice through the use of authentic clinical cases. It links theory to practice, through the application of knowledge to the cases, using inquiry-based learning methods." Its impact "can reach from simple knowledge gains to changing patient care outcomes". ${ }^{6}$ Moreover, two suggestions that appeared in the survey were: "Journal Club - discussion of key points of landmark articles pertaining to a relevant patient case" and "evidence-based cases and associated questions". Both comments suggested that some learners desire more emphasis on CBL and evidence-based medicine (EBM) to enhance the educational experience of the Huddle even more.

Most of the residents also agreed that the Huddle can help them improve their teaching skills and understand Hospital Medicine more and give them pearls in managing patients admitted to general medical wards. Most importantly, they viewed it as a tool to create a better educational environment during their inpatient rotation. This is encouraging since one of the main goals of the Huddle is to create an environment which can enhance the educational and learning experience of medical residents during one of their busiest residency training rotations. The Huddle appears to meet some of their needs for collaborative education and learning while taking care of sick patients in medical wards.

The fact that most of the respondents preferred their peers to teach during the Huddle - with faculty serving as facilitators - supports the notion that "teaching with flat hierarchies" with all its inherent advantages appears to be an appealing method of teaching for our learners. ${ }^{7}$ This is probably because it creates a friendly and less formal didactic practice to learn directly from peers, under the supervision of attendings. Residents know that this activity is not graded and is created primarily to gather all residents and faculty who are working in medical wards to discuss topics relevant to what they are currently doing and raise questions and concerns that face them during their rotation.

Although the first-year experience with the Hospitalist Huddle was promising, it still needs to be refined to maximize its benefits. There are still some challenges that need to be examined. One issue involved setting a reliable reminder tool for the presenting resident at the beginning of the week to make sure he/she has enough time to prepare his/her topic and materials. The presenting resident usually receives an email with instructions about goals of the Huddle and expectations. On a couple of occasions, the email was not sent and residents did not prepare for the session and it was canceled. Also, there is a need to improve the awareness of the activity among the residents and students who are rotating in medical wards, so that the Huddle starts on time and all members of the three teams are ready and prepared for the session. There is a need to encourage residents to choose Hospital Medicine topics which are not usually taught in residency didactic lectures (e.g., "What is safe discharge?", "Inpatient management of pain", and so on). As previously mentioned, learners seem to wish for more of CBL and EBM in the Huddle and there is a need to develop a standardized format which satisfies this request, but at the same time does not diminish residents' autonomy and sovereignty to choose their own topics and the way they want to deliver them. Few responses from PGY-3 residents were obtained, probably because by the end of the academic year, they are usually busy preparing for graduation, and applying for fellowships or job. More participation might have added more suggestions from residents to improve the Huddle from their perspective.

A few ideas and suggestions were brought up to address these issues with the goal of improving the educational value of the Huddle in the future. The email reminder will be sent earlier than before and the schedule for the whole academic year will be disseminated to all the residents at the beginning of the academic year and periodically. Attendants (medical students and residents) will be requested to fill out an anonymous, short electronic evaluation after each session. They will be asked to evaluate elements such as the relevance of the topic discussed to their daily practice in the inpatient setting, the clarity of the message intended to be delivered by the end 
of the session, the effort made by the presenting resident to make the session interactive, and so on. Furthermore, one way to test knowledge acquisition is to ask the attendant in that survey to mention two or three new clinical information or pearls that he/she retained at the end of the session. These evaluations can be accessed by the supervising hospitalist who can subsequently formulate and give constructive feedback to the presenting residents to help them improve the content and presenting style for future sessions. A real case and a recent article related to the topic can be requested to be sought, prepared, and presented briefly in each session to emphasize CBL and EBM. Moreover, to help residents understand the goals of the Huddle, a workshop run by hospitalists can be created to train the interns at the end of their internship year, since they will be the ones responsible for teaching their peers the year after. During such a workshop, interns can be educated about presentation skills, Hospital Medicine literature review, and advice and suggestions about the general structure of the Huddle.

\section{Conclusion}

Peer-to-peer teaching or teaching with flat hierarchies can be an appealing method of teaching Hospital Medicine to medical residents and students during their busy medical wards rotation. The Hospitalist Huddle is a weekly educational activity that was established by our Hospitalist Division a year ago to enhance this concept among medical residents and students and was perceived positively, as shown in a survey disseminated at the end of the first year of its establishment. Our goal now is to improve it during the coming academic years in terms of content, delivery and presenting style, standardizing, and educational value, and to utilize it as a tool that can help learners to be better medical educators in the future.

\section{Acknowledgments}

I would like to thank Dr Steven Stoltz, the director of the Hospitalist Division in the Department of Medicine in our institution, for his support to establish the idea of the Hospitalist Huddle and his continued contribution to be a facilitator at times during some of the sessions. Also, I would like to acknowledge Drs Paul Mills and Robin Whitney for their suggestions and advice in writing this paper.

\section{Disclosure}

The author reports no conflicts of interest in this work.

\section{References}

1. Wachter RM, Goldman L. The emerging role of "hospitalists" in the American health care system. N Engl J Med. 1996;335(7):514-517.

2. Wachter RM, Goldman L. Zero to 50,000 - The 20th Anniversary of the Hospitalist. N Engl J Med. 2016;375(11):1009-1011.

3. Ratelle JT, Dupras DM, Alguire P, Masters P, Weissman A, West CP. Hospitalist career decisions among internal medicine residents. $J$ Gen Intern Med. 2014;29(7):1026-1030.

4. Society of Hospital Medicine. Definition of a Hospitalist and Hospital Medicine. 2016. Available from: https://www.hospitalmedicine.org/ Web/About_SHM/Hospitalist_Definition/About_SHM/Industry/ Hospital_Medicine_Hospital_Definition.aspx?hkey=fb083d78-95b84539-9c5b-58d4424877aa. Accessed July 9, 2017.

5. Ten Cate O, Durning S. Peer teaching in medical education: twelve reasons to move from theory to practice. Med Teach. 2007;29(6):591-599.

6. Thistlewaite JE, Davies D, Ekeocha S, et al. The effectiveness of case based learning in health professional education. A BEME systematic review. BEME guide number 23. Med Teach. 2012;34(6):E421-E444.

7. Browne J and Read J. Editorial: Medical Students and Postgraduate Trainees as Medical Educators: peer learning is everywhere. 2017. Available from: https://www.mededpublish.org/manuscripts/1063/v1. Accessed July 9, 2017. reviewed, open access journal that aims to present and publish research on Medical Education covering medical, dental, nursing and allied health care professional education. The journal covers undergraduate education, postgraduate training and continuing medical education

including emerging trends and innovative models linking education, research, and health care services. The manuscript management system is completely online and includes a very quick and fair peer-review system. Visit http://www.dovepress.com/testimonials.php to read real quotes from published authors. 